\title{
SISTEMA DE PRODUÇÃO DO CAFÉ TRADICIONAL NO ESTADO DO PARANÁ - BRASIL: ANÁLISE DE INDICADORES DE CUSTOS, PRODUTIVIDADE, RENDA E CRÉDITOS DE CARBONO
}

\author{
Irene Domenes Zapparoli ${ }^{1}$ \\ Marcia Regina Gabardo da Câmara ${ }^{2}$ \\ Joel Ferracioli $^{3}$ \\ Emerson Guzzi Zuan Esteves ${ }^{4}$ \\ Daniela Carla Monteiro 5
}

\begin{abstract}
RESUMO: O objetivo do artigo é analisar a viabilidade e a sustentabilidade econômica da produção de café tradicional das unidades produtivas no Paraná. Os procedimentos metodológicos envolvem a discussão da literatura de Economia e Ecologia Ambiental. As informações básicas utilizadas neste trabalho foram obtidas através dos dados da SEAB/DERAL (2012), cujas propriedades rurais representam os plantios de café tradicional do sistema de produção predominante no Paraná. Os dados refletem padrões médios das regiões paranaenses e podem diferir individualmente de um local para outro. A análise e a discussão de indicadores de viabilidade econômico-social e sequestro de carbono permitem verificar que as árvores demandam uma quantidade muito grande de carbono para se desenvolver e acabam tirando esse elemento do ar. $\mathrm{O}$ estudo conclui que $\mathrm{o}$ processo natural contribui para diminuir consideravelmente a quantidade de $\mathrm{CO}_{2}$ na atmosfera: cada hectare de outras florestas em desenvolvimento é capaz de absorver de 150 a 200 toneladas de carbono. E que investimentos na busca de melhoria das técnicas utilizadas, da certificação de produtos, do bem-estar das famílias produtoras incrementarão a sustentabilidade da produção cafeeira e o desenvolvimento econômico de cada região especializada em café.

Palavras-chaves: Análise Econômica. Sistema de Produção. Seqüestro de carbono.
\end{abstract}

ABSTRACT: The aim of this paper is to analyze the economic feasibility of traditional coffee production. The methodological procedures involve the discussion of the literature of economics and environmental ecology. The data used in the article was collected from SEAB/DERAL (2012), whose properties represent the rural plantations of coffee the traditional production system prevalent in Paraná. The data reflect the mean standard from Paraná regions and may differ individually from one location to another. The analysis and discussion of indicators of social and economic feasibility of carbon sequestration show that the trees require a large amount of carbon to grow and end up taking the element of air. The study concludes that the natural process helps to reduce considerably the amount of $\mathrm{CO}_{2}$ in the atmosphere: each hectare of forest absorbs from 150 to 200 tons of carbon. And investments in search of improved techniques, product certification, and the welfare of the producer families will increase the sustainability of coffee production and economic development of each region specializes in coffee.

Key Words: Economic Analysis. Production System. Carbon sequestration.

\footnotetext{
${ }^{1}$ Professora do Departamento de Economia da Universidade Estadual de Londrina e Coordenadora do Curso de Especialização de Economia do Meio Ambiente - Universidade Estadual de Londrina (UEL) e Diretora do Núcleo de Pesquisas do Meio Ambiente (NEMA/UEL). E-mail: zapparoli@uel.br.

${ }^{2}$ Doutora em Teoria Econômica pela Universidade de São Paulo, coordenadora do Programa de Pós Graduação em Economia - PPE/UEL. E-mail: mgabardo@ sercomtel.com.br.

${ }^{3}$ Mestrando do Programa de Pós-Graduação em Economia (PPE/UEL). E-mail: joelferracioli@uol.com.br.

${ }^{4}$ Mestrando do Programa de Pós-Graduação em Economia (PPE,/UEL). E-mail: esteves@ sercomtel.com.br.

${ }^{5}$ Mestrando do Programa de Pós-Graduação em Economia(PPE/UEL). E-mail:danielamonteiro31@ yahoo.com.br Recebido em: 23/04/2012
}

Aceito em: 14/11/2012 


\section{INTRODUÇÃO}

O café tem grande capacidade de absorção de mão de obra, é responsável pela transferência de renda para outros setores da economia e pela contribuição à formação de capital do setor agrícola nacional. A crise da cafeicultura paranaense agravou-se com a geada de 1975, acarretando num custo de recuperação das lavouras elevado. Estes fatores climáticos e econômicos levaram os produtores a substituir a cultura do café, por outras mecanizadas e mais viáveis, como o milho e o binômio soja-trigo. Mesmo assim, o café tem sido cultivado nas regiões do Norte Pioneiro, Norte, Noroeste e Oeste do Estado, em função da infra-estrutura disponível e da possibilidade de exploração de microclimas mais favoráveis (EMBRAPA, 1997). A questão de pesquisa que o presente artigo pretende responder e verificar se é viável e sustentável economicamente a produção de café tradicional no Estado do Paraná.

O objetivo é analisar a viabilidade e a sustentabilidade econômica da produção familiar do café tradicional das unidades produtivas no Paraná. Os objetivos específicos compreendem: verificar a relação entre sequestro de carbono e certificação ambiental na produção de café tradicional; identificar os estágios em que se encontram as ações que visem ao desenvolvimento e até o renascimento da cultura do café convencional e orgânico no Estado do Paraná; caracterizar os mercados envolvidos diretamente no processo de comercialização do café tradicional produzido no Paraná; e calcular o sequestro de carbono na cultura do café tradicional. A base de dados da SEAB/DERAL (2012) inclui propriedades rurais que representam os plantios de café tradicional do sistema de produção predominante no Paraná e os dados refletem padrões médios das regiões paranaenses.

O estudo está dividido em seis partes: introdução, discussão dos fundamentos teóricos, relação entre sequestro de carbono e certificação ambiental para o café tradicional, procedimentos metodológicos, análise de resultados e conclusão.

\section{FUNDAMENTOS TEÓRICOS: DA ECONOMIA À ECOLOGIA AMBIENTAL}

No contexto, do debate acadêmico sobre desenvolvimento sustentável se concentra em duas correntes principais de interpretação. De um lado a chamada economia ambiental que analisa os recursos naturais na lógica do mercado e considera que os mesmos não representam, a longo prazo, um limite absoluto à expansão da economia. E de outro, a economia ecológica, que vê o sistema econômico como um subsistema de um todo maior que o contém, impondo uma restrição absoluta à sua expansão. Em outras palavras, a longo 
prazo, a sustentabilidade do sistema econômico não é possível sem estabilização dos níveis de consumo per capita de acordo com a capacidade de carga do planeta (ROMEIRO, 2010).

Segundo Georgescu-Roegen (1976), o sistema econômico não pode contrariar as leis da física. A segunda lei da termodinâmica estabelece que o grau de degeneração de um sistema isolado tende a aumentar com o tempo, impedindo a existência de moto-perpétuos (uma máquina capaz de produzir trabalho ininterruptamente utilizando a mesma energia). Da mesma forma, o sistema econômico não pode se mover para sempre sem entrada de recursos e saída de resíduos, sendo o sistema produtivo, portanto, linear e aberto, e não circular.

Apesar de considerar o diagrama do fluxo circular da renda uma simplificação bastante útil do sistema econômico, Georgescu-Roegen (1976), considera a ideia de que tanto os bens de capital quanto a força de trabalho são mantidos constantes não deixa de ser uma ficção, pois o processo econômico muda contínua, quantitativa e qualitativamente máquinas e equipamentos.

Romeiro (2010) ressalta que a obra de Georgescu-Roegen é relevante no sentido da introdução da ideia de irreversibilidade e de limites na teoria econômica, que decorre da segunda lei da termodinâmica (lei da entropia) em contraposição à primeira lei da termodinâmica (sobre a transformação da matéria), na qual essa ideia não faz sentido e sobre a qual se baseia implicitamente a teoria econômica convencional.

A magnitude da escala atual das atividades humanas tem levantado o problema do limite da capacidade de suporte do planeta Terra, seja como fornecedor de bens e serviços naturais, seja como receptor dos rejeitos das atividades humanas de consumo e produção industrial, conforme representação do circuito econômico ampliado (Figura 1).

Figura 1 - Circuito Econômico Ampliado

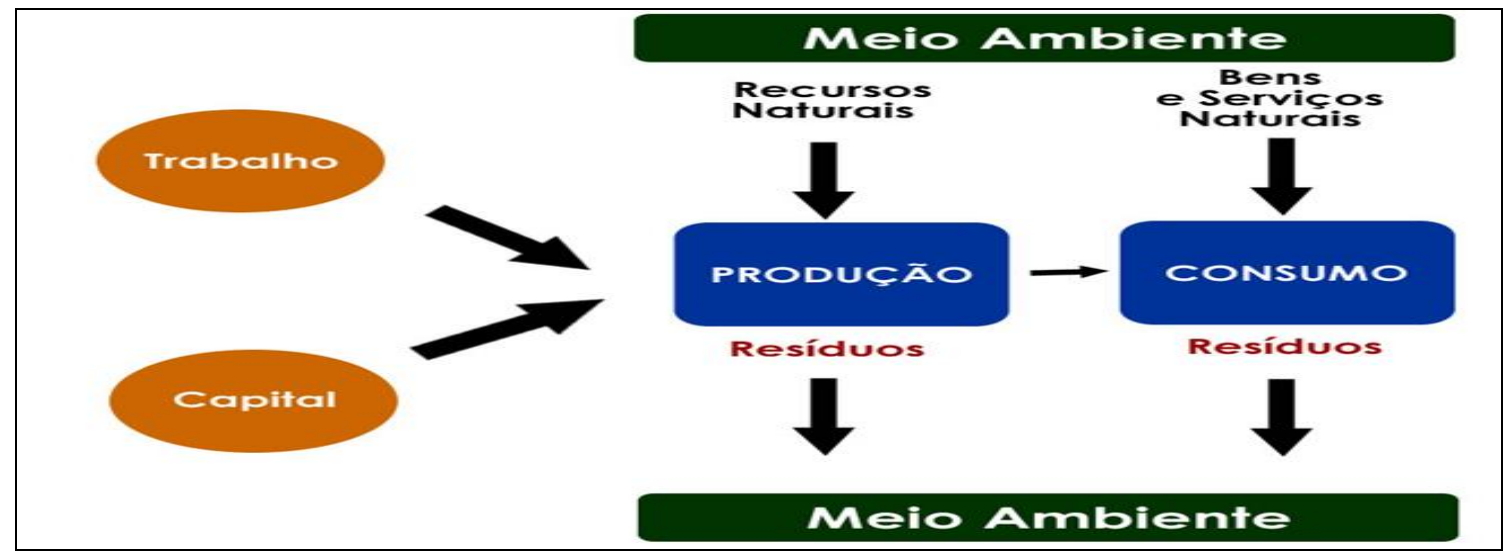

Fonte: Adaptado de Clemente e Higachi (2000). 
Durante muitos anos, crescimento econômico e preservação ambiental foram tratados como sendo incompatíveis, "entretanto, esses aspectos não deveriam ser entendidos como abordagem contraditória, já que a evolução da economia está atrelada a evolução da própria natureza" (DAMASCENO; MATA, 2002, p. 48).

Há um consenso de que é plenamente possível e conveniente a conciliação de preservação ambiental e crescimento econômico. "Torna-se inexorável conceber uma relação necessária e urgente, na dinâmica econômica, que venha gerar uma real parceria com um meio ambiente construtivo e produtivo, sendo esta pareceria não depreciativa e efetivamente sustentável" (VIEIRA; ROCHA, 2005, p. 2).

O conceito de desenvolvimento sustentável traz novas abordagens ao conceito de economia, considerando os cenários sociais, econômico, político, cultural e meio ambiente, este último, intimamente ligado à questão de escassez de recursos naturais. "Furtar à economia a possibilidade de gerar limites e possibilidade para o planejamento de uma sociedade com uso extremo do meio ambiente, seria um delito à sobrevivência" (VIEIRA; ROCHA, 2005, p.3).

Segundo Vieira e Rocha (2005, p. 3), a questão ambiental no Brasil, revela aspectos de mudança de reestruturação do espaço competitivo de mercado, em função das transformações do setor produtivo sob o viés ambiental. Além disso, revela mudanças na ideia de sustentabilidade, através da participação governamental e de instituições como fundações, ONG's e entidades privadas envolvidas na questão ambiental.

Outro aspecto importante que se deve observar é que a preocupação das indústrias com o meio ambiente raramente é suscitada apenas pela consciência da escassez de recursos naturais, em geral, surge frente a exigências de mercado, [...] "dessa forma, podemos compreender que a Economia Ambiental, ou Economia do Meio Ambiente, deve ser encarada como uma arma competitiva, como parte da estratégia de desenvolvimento adotada pelas empresas que pretendem lançar-se ou mesmo permanecer atuantes no mercado" (COSTA, 2005, p. 303).

No processo de produção utiliza-se capital transformado, capital social e capital natural. A lavoura de café possui desenvolvimento tecnológico para o capital transformado e mão de obra qualificada para atender ao capital social, mas precisa ser vista como aliada ao capital natural no seu processo produtivo, a selagem vem se apresentando como estudos recentes na alternativa viável de preservação ambiental. 


\section{RELAÇÃO ENTRE SEQUESTRO DE CARBONO E CERTIFICAÇÃO AMBIENTAL PARA O CAFÉ}

No final do século XX e início do século XXI, os estudiosos do meio-ambiente têm discutido a relação entre desenvolvimento, sustentabilidade e meio ambiente, de forma a tornar possível o desenvolvimento sem desprezar o aspecto da sustentabilidade. $\mathrm{O}$ sequestro de carbono e consequentemente a comercialização das Reduções Certificadas de Emissões (RCE), tem como objetivo proporcionar um elo de ligação entre o desenvolvimento e a preservação do meio ambiente.

A busca pelo crescimento econômico fez com que o setor agrícola buscasse mecanismos e novas tecnologias que possibilitassem cada vez mais lucro, mas com os frequentes problemas climáticos e com a ocorrência de grandes catástrofes naturais, causadas pela degradação ambiental, a preocupação com a preservação e o manejo dos recursos naturais vem aumentando aliado à preocupação do consumidor com o aumento da emissão dos Gases Efeito Estufa (GEE).

\subsection{Sequestro de carbono}

Na Conferência das Partes (COP-3) realizada em 1997, em Kyoto, Japão, diante da ocorrência do aquecimento global, devido ao aumento do efeito estufa provocado por causas antrópicas, em 1990, a Assembléia Geral da Organização das Nações Unidas (ONU) estabeleceu o comitê Intergovernamental de Negociação para a Convenção-Quadro sobre Mudança de Clima, o que deu início as negociações que chegariam ao tão discutido Protocolo de Kyoto. Por meio do Protocolo de Kyoto foram criados três mecanismos de flexibilização: São eles: Implementação Conjunta (IC); Comércio de Emissões (CE); Mecanismo de Desenvolvimento Limpo (MDL) (BRASIL, MCT, 2011)

O Mecanismo de Desenvolvimento Limpo (MDL) tem a finalidade de atingir o desenvolvimento sustentável e ajudar os países a adequarem-se aos seus compromissos quantitativos de limitação e redução de emissões dos gases causadores do efeito estufa. É bem verdade que, esse processo é um efeito natural que mantém a vida na terra. $\mathrm{O}$ que se pode tornar catastrófico é a ocorrência de um agravamento do efeito estufa que desestabilize o equilíbrio energético no planeta e origine um fenômeno conhecido como aquecimento global (ZÔMPERO et al., 2008). 
Nesse momento vale lembrar que o gás carbônico $\left(\mathrm{CO}_{2}\right)$ e outros gases, como o metano (CH4) e o óxido nitroso (N2O), hexafluoreto de enxofre (SF6), hidrofluorcarbonetos (HFCS) e as famílias dos perfluorcarbonetos (PFCS), são alguns dos gases que mais colaboram para que os raios infravermelhos do sol fiquem retidos na atmosfera, os chamados GEE. A Tabela 1 traz o levantamento dos GEE na Terra.

Tabela 1 - Concentração dos Gases de Efeito Estufa (GEE), 2010

\begin{tabular}{cc}
\hline Gases de Efeito Estufa "Extra" & \% em volume \\
\hline Dióxido de carbono & 49 \\
Metano & 18 \\
CFC's & 14 \\
Óxido nitroso & 6 \\
Outros gases & 13 \\
\hline
\end{tabular}

Fonte: Portal São Francisco (2012)

A presença desses gases teve um crescimento excepcional desde a Revolução Industrial, em meados do século XVIII, que mudou definitivamente a relação entre o homem e a natureza. Na era pré-industrial, a concentração de $\mathrm{CO}_{2}$ na atmosfera era de 280 ppm (partes por milhão). Hoje pairam em nosso ar mais de 370 ppm de $\mathrm{CO}_{2}$, um número que vem aumentando à taxa de $0,4 \%$ ao ano desde 1980. (BRASIL, MCT, 2011).

O aumento da emissão dos GEE por fontes antrópicas, determinante do aquecimento global, tem trazido grande preocupação à sociedade moderna. Os GEE são em quantidades maiores especialmente em locais com demanda crescente de energia, em maior parte de natureza não-renovável, decorrente, sobretudo, do crescimento populacional. Mudanças climáticas podem resultar em externalidades negativas diversas para as gerações futuras. (BRASIL, MAPA, 2011).

Os reservatórios naturais, como florestas, oceanos, solos rochas e outros, são considerados sumidouros ou depósitos de $\mathrm{CO}_{2}$, por retirar o seu excesso da atmosfera. Pode-se observar que estes estão perdendo essa capacidade por saturação do sistema com queimadas, desmatamentos alterações do solo, entre outros, causando assim o aumento anormal nas concentrações de $\mathrm{CO}_{2}$. (BRASL, MAPA, 2011).

Em virtudes dessas considerações, teme-se o agravamento do efeito estufa, com alterações catastróficas decorrentes do aquecimento global como, o aumento do nível do mar; alteração do suprimento de água doce; maior número de ciclones; súbito ressecamento do solo, tempestades de chuva e neve fortes e mais frequentes, entre outros. 
Nesse sentido, pode-se observar que o princípio básico da sustentabilidade não está sendo aplicado.

A definição mais difundida sobre sustentabilidade é a da Comissão Brundtland, conforme Claro; Claro e Amâncio (apud WCED, 2008), a qual considera que o desenvolvimento sustentável deve satisfazer as necessidades da geração presente sem comprometer as necessidades das gerações futuras de suprir as suas.

Portanto, faz-se de extrema importância fazer referência ao Relatório de Brundtland, da década de 80, que apontou caminhos para o desenvolvimento sustentável, a Agenda 21 que foi a mola propulsora para a sustentabilidade e em seguida a Carta da Terra que representa um marco na história do planeta, sendo uma referência ética para todos os povos. Donaire (1999) corrobora com essa ideia ao tratar esse tema, destacando que os principais eixos desse relatório são o crescimento econômico, a equidade social e o equilíbrio ecológico.

Conforme destacado pelo Ministério do Meio Ambiente (BRASIL, MMA, 2011), a Agenda 21 pode ser definida como um instrumento de planejamento para a construção de sociedades sustentáveis, que concilia métodos de proteção ambiental, justiça social e eficiência econômica. Em seguida, também de acordo com o MMA (BRASIL, 2011), a Carta da Terra é um instrumento que vem somar forças para gerar uma sociedade sustentável global baseada no respeito à natureza, nos direitos humanos universais, na justiça econômica e numa cultura da paz.

Acrescenta-se a tudo isso que a sustentabilidade é um modelo sistêmico que atualmente tem sido foco nas empresas como base para a adequação das novas exigências, tanto do mercado global quanto da sociedade. Existem cinco modelos de sustentabilidade, sendo estes: social, ecológica, espacial, cultural e econômica, conforme Forato (2010).

Ao abordar sobre sustentabilidade, Forato (2010) relata os cinco modelos:

a) Sustentabilidade social: entende-se como a criação de um processo de desenvolvimento sustentado por uma civilização com maior equidade na distribuição de renda e de bens, de modo a reduzir o abismo entre os padrões de vida dos ricos e dos pobres.

b) Sustentabilidade ecológica: é alcançada através do aumento da capacidade de utilização dos recursos; limitação do consumo de combustíveis fósseis e de outros recursos e produtos que são facilmente esgotáveis; redução da geração de resíduos e de poluição; através da conservação de energia e de recursos; e da reciclagem. 
c) Sustentabilidade espacial: é aquela que deve ser dirigida para a obtenção de uma configuração rural-urbana mais equilibrada, e uma melhor distribuição territorial dos assentamentos humanos e das atividades econômicas.

d) Sustentabilidade cultural: inclui a procura por raízes endógenas de processos de modernização e de sistemas agrícolas integrados, que facilitem a geração de soluções específicas para o local, o ecossistema, a cultura e a área.

e) Sustentabilidade econômica: deve ser alcançada através do gerenciamento e alocação mais eficiente dos recursos e de um fluxo constante de investimentos públicos e privados.

Para assegurar a existência das condições favoráveis à vida precisamos viver de acordo com a capacidade do planeta, ou seja, de acordo com o que a Terra pode fornecer e não com o que gostaríamos que ela fornecesse. Avaliar até que ponto o nosso impacto já ultrapassou o limite é essencial, pois só assim poderemos saber se vivemos de forma sustentável. (WWF, 2011).

Vale lembrar que desde a década de 80 a demanda da população mundial por recursos naturais é maior do que a capacidade do planeta em renová-los. Esta exploração da natureza, de forma descontrolada, que gera o esgotamento do capital natural mais rápido do que sua capacidade de renovação, não pode perdurar, pois, desta forma, enfrentaremos em breve uma profunda crise socioambiental e uma disputa por recursos. O desequilíbrio da sustentabilidade do planeta, com a excessiva exploração da natureza, causa a perda acelerada da biodiversidade, ou seja, o desaparecimento ou declínio do número de populações de espécies de plantas e animais. (WWF, 2010).

Em 1992, no Rio de Janeiro, foi realizado a ECO 92 que resultou em uma série de convenções, acordos e protocolos onde, apesar de alguns não terem sido efetivados, foi adotada a Convenção-Quadro das Nações Unidas sobre Mudança do Clima. Ela possibilitou a adoção de compromissos adicionais em resposta a mudanças no conhecimento científico e nas disposições políticas. (BRASIL, MCT, 2011).

O objetivo final desta Convenção é a estabilização das concentrações de GEE na atmosfera num nível que previna a interferência antrópica perigosa no sistema climático do planeta. Esse nível deverá ser alcançado num prazo suficiente que permita aos ecossistemas adaptarem-se naturalmente à mudança do clima, assegurando que a produção de alimentos não seja ameaçada e que permita ao desenvolvimento econômico prosseguir de maneira sustentável. (BRASIL, MCT, 2011). 
A primeira revisão da adequação dos compromissos dos países desenvolvidos ocorreu em Berlim, em 1995. E em dezembro de 1997 foi realizado novamente, desta vez em Kyoto no Japão.

A conferência culminou na decisão, por consenso, de adotar um Protocolo segundo o qual os países industrializados reduziriam suas emissões combinadas de gases de efeito estufa, em pelo menos 5,2\% em relação aos níveis de 1990 até o período entre 2008 e 2012. O que equivale a 714 milhões de $\mathrm{CO}_{2}$. Esse compromisso, com vinculação legal, promete produzir uma reversão da tendência histórica de crescimento das emissões iniciadas nesses países há cerca de 150 anos. (BRASIL, MCT, 2011).

O Protocolo de Kyoto foi aberto para assinatura em 16 de março de 1998 para entrar em vigor 90 dias após a sua ratificação, por pelo menos 55 Partes da Convenção (porém, só entrou em vigor somente em 16 de fevereiro de 2005, sem a participação dos Estados Unidos), incluindo os países desenvolvidos que contabilizaram pelo menos 55\% das emissões totais de $\mathrm{CO}_{2}$ em 1990. (BRASIL, MCT, 2011).

A Implementação Conjunta (IC), prevista no artigo $6^{\circ}$ do Protocolo, estabelece a possibilidade da constituição e transferência do crédito de emissões de GEE do país em que o projeto está sendo implementado para o país emissor, de maneira que esse último possa adquirir créditos e, em troca, constituir fundos para o desenvolvimento de projetos em outros países. (SISTER, 2008).

O Comércio Internacional de Emissões (CIE) foi previsto no artigo $17^{\circ}$ do Protocolo, onde por meio dele os países poderiam negociar o limite de emissões com outros países com o objetivo de cumprir suas metas de redução. (SISTER, 2008). O Mecanismo de Desenvolvimento Limpo (MDL) está previsto no artigo 12 do Protocolo. Este mecanismo, que apenas os países em desenvolvimento podem adotar, é constituído através da retirada ou da não-emissão dos gases poluentes na atmosfera, gerando assim os créditos chamados Reduções Certificadas de Emissões (RCE).

Em 2012, a previsão era de que expiraria o Protocolo de Kyoto, após essa data haveria à inclusão dos países em desenvolvimento como Brasil, África do Sul, México, China, Coréia do Sul, Índia e Indonésia, na meta de redução de emissões. (BRASIL, MCT, 2011). A Conferência das Partes (COP-11) realizada em 2005, em Montreal, Canadá, que foi realizada em paralelo a Primeira Conferência das Partes do Protocolo de Kyoto (COP/MOP-1). Foram duas reuniões de extrema importância, uma vez que a COP-11 e a COP/MOP-1 foram as primeiras conferências realizadas após a entrada em vigor do Protocolo de Kyoto, em 16 de fevereiro de 2005. As discussões se pautavam nas 
perspectivas para o segundo período do acordo, pós 2012. As associações ambientais da Europa apontam para a necessidade de uma redução de 20 a 30\% das emissões de Gases de Efeito Estufa (GEE), com base no ano de 1990, até 2030,e de 60\% a 80\%, até 2050.

De acordo com as regras estabelecidas pela Organização das Nações Unidas (ONU), as empresas dos países desenvolvidos poderão financiar a implementação e manutenção de projetos de redução ou remoção dos GEE, mediante investimentos em tecnologias mais eficientes, substituição de fontes de energia fósseis por renováveis, racionalização do uso da energia, florestamento e reflorestamento, entre outros; e em compensação, poderão emitir, em seus territórios, o que for evitado no país anfitrião do projeto. (LOPES, 2002).

O MDL permite a certificação de projetos de redução de emissões nos países em desenvolvimento e a posterior venda das RCE, que é uma tonelada métrica de gás carbônico, para serem utilizadas pelos países desenvolvidos como modo suplementar de cumprirem suas metas. (BRASIL, MCT, 2011).

Esse mecanismo deve implicar em reduções de emissões adicionais àquelas que ocorreriam na ausência do projeto, garantindo benefícios reais, mensuráveis e de longo prazo para a mitigação da mudança do clima. (BRASIL, MCT, 2011).

Há uma série de critérios para o reconhecimento desses projetos, entre eles, o de estarem alinhados às premissas de desenvolvimento sustentável do país hospedeiro, definidos por Autoridade Nacional Designada (AND). No Brasil, essa autoridade é a Comissão Interministerial de Mudança do Clima. Somente após ser aprovado por ela, o projeto pode ser submetido à ONU para avaliação e registro. (MCT, 2011).

Toledo, Ballalai e Feijó (2009) corroboram com essa ideia ao afirmar que, os projetos de MDL devem seguir as etapas que os habilitam à requisição da RCE, para que surtam efeitos jurídicos eficazes. O processo de certificação do projeto, disciplinado pelo Protocolo de Kyoto, são apresentados na figura 2 que observam as seguintes etapas: Elaboração do Documento de Concepção do Projeto; Validação; Aprovação; Registro; Monitoramento; Verificação/Certificação; Emissão e aprovação das RCE.

Figura 2 - Procedimentos Necessários para Obtenção de Redução Certificada de Emissão. 


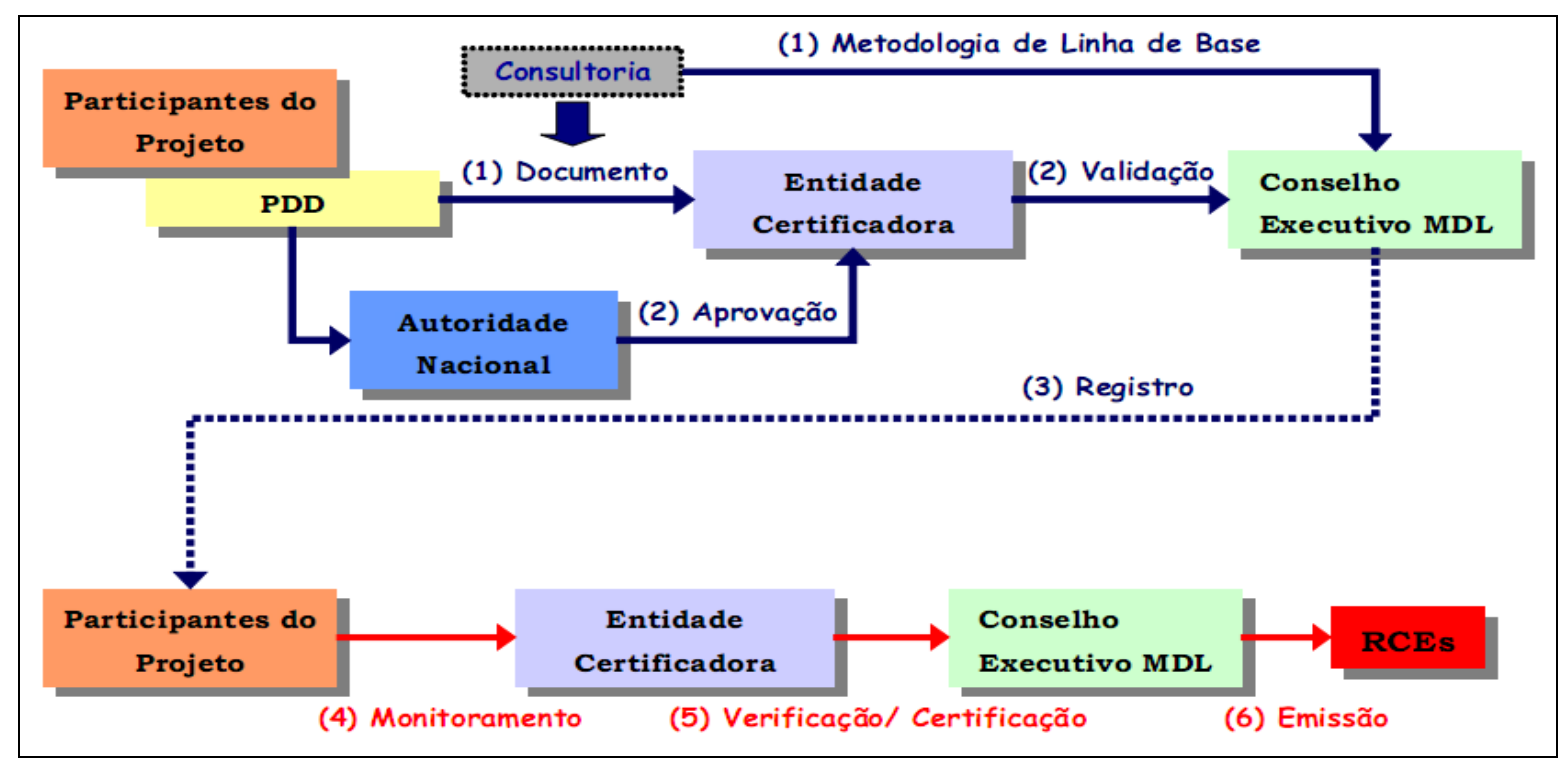

Fonte: Conejero (2006)

De acordo com Toledo, Ballalai e Feijó (2009), qualquer pessoa pode assumir o compromisso de neutralizar carbono, tanto pessoas físicas quanto jurídicas, sendo assim uma oportunidade do cidadão comum e das empresas adotarem posturas de conscientização ambiental.

Os projetos de MDL precisam caracterizar a redução das emissões de GEE, portanto a implementação de cada projeto de MDL irá contribuir com a sustentabilidade do planeta, diminuindo assim a Pegada Ecológica. Os subtítulos a seguir descreverão todas as etapas necessárias que todo processo de certificação de projetos de MDL precisam cumprir para obtenção das RCE, de acordo com Toledo, Ballalai e Feijó (2009) e o MCT (BRASIL, MCT, 2011).

A elaboração do Documento de Concepção de Projeto (DCP) possui uma estrutura preestabelecida pelo Conselho Executivo do MDL, o chamado documento base, um auxiliar aos Estados membros na apresentação de informações necessárias à elaboração do DCP.

Esse documento deverá, em síntese, conter os seguintes elementos: Descrição da atividade do projeto; Os participantes da atividade do projeto; Metodologia da linha de base; Metodologias para cálculo da redução de emissões de gases de efeito estufa; Metodologia para o estabelecimento dos limites da atividade de projeto, bem como das fugas; Plano de monitoramento; Definição do período de obtenção de créditos; Descrição das informações para demonstrar a adicionalidade da atividade de projeto; Informações sobre impactos ambientais; Comentários dos atores e informações quanto à utilização de fontes adicionais de financiamento. 
Sendo que os responsáveis por essa etapa do processo são os participantes do projeto. A validação é o segundo passo no Brasil e corresponde ao processo de avaliação independente de uma atividade de projeto por uma Entidade Operacional Designada (EOD), no tocante aos requisitos do MDL, com base no DCP. Após a avaliação independente, será emitido um Relatório de Validação, concluindo pela aprovação ou não do projeto, ao qual se dará publicidade.

A aprovação, por sua vez, é o processo pelo qual a Autoridade Nacional Designada (AND) das partes envolvidas, que confirmam a participação voluntária, e a AND do país onde são implementadas as atividades do projeto de MDL, atestam que dita atividade contribui para o desenvolvimento sustentável do país.

Com relação ao Brasil, os projetos são analisados pelos integrantes da Comissão Interministerial de Mudança Global do Clima (CIMGC), que avaliam o relatório de validação e a contribuição da atividade do projeto para o desenvolvimento sustentável do país, segundo cinco critérios básicos a seguir: Distribuição de renda; Sustentabilidade ambiental local; Desenvolvimento das condições de trabalho e geração líquida de emprego; Capacitação e desenvolvimento tecnológico; Integração regional e articulação com outros setores.

O registro das atividades do projeto como um MDL é uma exigência de natureza formal muito importante no ciclo do projeto, pois, a partir desse momento ocorre a oficialização de sua existência na ONU. Registro é a aceitação formal, pelo Conselho Executivo, de um projeto validado como atividade de projeto do MDL. A aprovação de projetos no Conselho Executivo do MDL é subseqüente à aprovação pela Autoridade Nacional Designada.

A aprovação pela CIMGC é necessária para a continuidade dos projetos, mas não é suficiente para sua aprovação pelo Conselho Executivo, que analisa também a metodologia escolhida, a adicionalidade do projeto, entre outros aspectos. E o registro é o pré-requisito para o monitoramento, a verificação/certificação e emissão das RCEs relativas à atividade de projeto no âmbito do MDL.

$\mathrm{O}$ processo de monitoramento da atividade de projeto inclui o recolhimento e armazenamento de todos os dados necessários para calcular a redução das emissões de gases de efeito estufa, de acordo com a metodologia de linha de base estabelecida no DCP (Documento de Concepção do Projeto), que tenham ocorrido dentro dos limites da atividade de projeto e dentro do período de obtenção de créditos. Os participantes do projeto serão os responsáveis pelo processo de monitoramento. 
Durante essa fase, as reduções de emissões de GEE alcançadas pelo projeto ao longo de um determinado período de operações serão quantificadas. Não há uma definição de frequência para a realização desse processo, podendo o desenvolvedor realizar quantos monitoramentos achar conveniente. A verificação e certificação deverão ser feitas através da submissão do Relatório de Monitoramento a uma EOD diferente do qual a que realizou a validação do projeto.

Esse procedimento é um processo de auditoria periódica e independente, tendo como objetivo revisar os cálculos acerca da redução de emissões de GEE ou de remoção de $\mathrm{CO}_{2}$ resultantes de uma atividade de projeto do MDL, para assim certificar da correta implementação do Plano de Monitoramento que é enviado ao Conselho Executivo por meio do Documento de Concepção do Projeto (DCP).

Esse processo é feito com o intuito de verificar a redução de emissões que efetivamente ocorreu. Após a verificação, o Conselho Executivo certifica que uma determinada atividade de projeto atingiu um determinado nível de redução de emissões de gases de efeito estufa durante um período de tempo específico.

A etapa final é quando o Conselho Executivo tem certeza de que, cumpridas todas as etapas, as reduções de emissões de gases de efeito estufa decorrentes das atividades de projeto são: reais, mensuráveis e de longo prazo, e, portanto, podem dar origem as RCEs.

As RCEs são emitidas pelo Conselho Executivo e creditadas aos participantes de uma atividade de projeto na proporção por eles definida e, dependendo do caso, podendo ser utilizadas como forma de cumprimento parcial dos compromissos quantificados de redução e limitação de emissão de gases de efeito estufa por parte dos países desenvolvidos que aderiram ao Protocolo de Kyoto.

A busca por qualidade em produtos agroindustriais está mostrando um crescimento constante na última década, fruto de mudanças nas preferências dos consumidores. Há consumidores dispostos a pagar mais por produtos que possuem alguns atributos desejados A possibilidade de diferenciação e segmentação de produtos é um entre os fatores mais relevantes que nos últimos anos estão influenciando a competitividade dos produtos agroindustriais. Em consequência disso, alguns atributos de qualidade, passíveis de certificação, estão sendo incorporado, como instrumento de concorrência do produto final.

Além disso, a crescente demanda, particularmente em países desenvolvidos, por produtos saudáveis e socialmente corretos, possibilita o surgimento de produtos diferenciados, com novos atributos. 


\subsection{Certificação ambiental}

A certificação de produtos é um procedimento que requer uma adaptação dos sistemas produtivos a uma série de regras estabelecidas pelas agências certificadoras, para fins de inspeção e emissão de certificado de conformidade. Este procedimento pode estar restrito não apenas à produção rural, como também a outros segmentos do sistema agroindustrial. Quando a certificação envolve todo o sistema, é necessário rastrear o caminho percorrido pelo produto, o que implica em monitoramento e controle das diversas etapas produtivas, para que o produto chegue ao seu consumidor final, com as garantias de seus atributos.

A reorganização do sistema agroindustrial para adaptação às regras de agências certificadoras traz uma série de impactos, tanto econômicos como sociais. Estes impactos não dizem respeito somente a mudanças nos sistemas de produção, mas também traduzem a flexibilidade de produtores e empresas para adaptação às transformações sociais.

Um dos efeitos socioeconômicos mais positivos da criação de novos mercados com atributos específicos é a possibilidade de incorporação de pequenos produtores nesse processo. Os mercados de produtos agrícolas, geralmente considerados commodities, apresentam vantagens como escala de produção e redução de custos. Os nichos de mercado, por outro lado, devido à presença de atributos de qualidade específicos, são adaptados à produção em pequena escala e emprego de mão de obra familiar.

As propriedades compreendidas entre 10 e 100 ha são responsáveis por $79 \%$ do total de propriedades cafeeiras e 51\% do número total de pés (VEIGA FILHO et al., 1985). Os pequenos produtores tem tido dificuldades para acompanhar as rápidas transformações tecnológicas e as crescentes exigências sanitárias, de qualidade e de regularidade para continuar no mercado. Esse segmento social tem como principal característica, o trabalho baseado no uso predominante e quase exclusivo da mão de obra familiar e competem com empresas agrícolas fortemente estruturadas e especializadas.

O sequestro de carbono para pequenos produtores comercializarem pode trazer um diferencial na competitividade com grandes empresas do setor que tem preocupação com a produção de escala.

\subsection{A Agricultura familiar}


As propriedades familiares, via de regra, têm como estratégia de sobrevivência a diversificação da produção, que se de um lado possibilita diminuir os riscos de perdas de safra e obter renda ao longo do ano, por outro lado, também pode facilitar o cultivo das culturas limpas de modo a auxiliar a preservação do meio ambiente. Dados recentes comprovam que a agricultura familiar emprega mais de $70 \%$ da mão de obra agrícola, além de contribuir com cerca de $60 \%$ da produção de alimentos consumidos pela população brasileira. No caso do feijão, essa produção chega a $70 \%$.

As políticas para o desenvolvimento deste setor têm sido muito debatidas e muitos investimentos têm sido feitos para melhorar a economia e a o bem-estar desta parcela da população. (BNDES, 2010). O Governo Federal, através do Programa Nacional de Fortalecimento da Agricultura Familiar (PRONAF) tem tomado iniciativas no sentido de fortalecer e estimular a agricultura familiar. Outras ações no sentido de possibilitar a assistência técnica e oferecer créditos para expansão rural estão sendo ampliadas, tanto por parte da iniciativa pública, quando da privada, garantindo renda e condições para o desenvolvimento da atividade.

As Instituições de Pesquisa e Desenvolvimento Agropecuário estão firmemente comprometidas com o desenvolvimento da Agricultura Familiar e investiram [...] em projetos destinados a aumentar o número de empregos, gerar produtos de qualidade e com menor custo, estabilizar a produção e a oferta de produtos básicos, além de preservar o meio ambiente. (EMBRAPA, 2000, p.4)

Ainda segundo o balanço de 2000 da EMBRAPA, os investimentos e benfeitorias nas pequenas propriedades, com tecnologias de incremento da produção e acesso à informação, a agricultura familiar dá um salto de qualidade. Ações institucionais têm garantido às comunidades rurais não apenas a subsistência, mas a capacidade de competir no mercado de alimentos. Na base dessas parcerias, a participação e organização da agricultura familiar apontam alternativas de sucesso, como o investimento em agroindústrias familiares, comunitárias e caseiras, que levam alimentos de qualidade e a preços acessíveis à mesa do consumidor. "O aspecto desafiante é fazer tudo isto em uma velocidade compatível com o processo de transformação que ocorre no Brasil e no mundo caracterizado por um mercado globalizado, aberto e competitivo" (PORTUGAL, 2004, p.4).

A agricultura familiar brasileira, que é potencialmente geradora de empregos, impulsiona a economia local, fazendo com que a renda oriunda da atividade agrícola circule dentro dos municípios, contribuindo para uma mudança do cenário agrícola nacional. 


\section{PROCEDIMENTOS METODOLÓGICOS}

Além dos dados do SEAB / DERAL (2012), o estudo coletou informações em campo para mensurar na própria lavoura do café, a biomassa vegetal total (BVT; t/ha); a biomassa de árvores vivas e mortas em pé (BA); o diâmetro altura do peito (DAP); biomassa total de árvores vivos em t/há (BAVT); biomassa total na parcela de $2 \mathrm{~m}$ x $25 \mathrm{~m}$ ou na de 5m x 100m (BTAV); biomassa total de árvores mortas em pé em t/há (BTAMP); biomassa de árvores mortas em pé dentro da parcela (BAMPP); biomassa total de árvores caídas mortas em t/há (BTACM); biomassa total das árvores caídas mortas na parcela de $2 \mathrm{~m}$ x $25 \mathrm{~m}$ ou na de $5 \mathrm{~m}$ x 100m (BACMP). O método utilizado é descritivo e utilizam-se as informações coletados nas lavouras de café pelo DERAL (2012) de forma a identificar os custos produtivos, os retornos financeiros, a taxa interna de retorno. (ALEGRE, AREVALO, MONTOYA, 2002).

Foram feitos cálculos para se verificar a viabilidade financeira e econômica do cultivo do café, levando em consideração os indicadores a seguir.

a) Indicadores associados à rentabilidade (ganho ou criação de riqueza) do projeto

- Valor Presente Líquido (VPL);

- Valor Presente Líquido Anualizado (VPLa);

- Taxa Interna de retorno (TIR);

- Índice Benefício / Custo (IBC).

b) Indicadores associados ao risco do projeto

- A Taxa Interna de retorno (TIR);

- Período de recuperação do Investimento (Pay-back).

A TIR é uma taxa de desconto hipotética que, quando aplicada a um fluxo de caixa, faz com que os valores das despesas, trazidos ao valor presente, seja igual aos valores dos retornos dos investimentos, também trazidos ao valor presente.

Entende-se como TMA a melhor taxa, com baixo grau de risco, disponível para aplicação do capital disponível. A TMA de 9,75\%, tendo com base a taxa SELIC (Sistema Especial de Liquidação e Custódia), foi coletada no site da Receita federal em 07 de março de 2012, bem como a cotação do preço do café, no site Globo Rural em 21 de março de 2012. A taxa 
de câmbio no dia 21 de março de 2012 de acordo com o site www.uol.com.br, era de R\$1,8205 para U\$ 1,00 .

Quando a TIR é maior do que a TMA; significa que o investimento é economicamente atrativo.

O Valor Presente Líquido (VPL) é uma função decrescente da TMA, significando que quanto maior for o piso mínimo de retorno exigido para o projeto (TMA) menor será o VPL e, por conseguinte, mais difícil fica a viabilização de projetos, ou seja, encontrar projetos com VPL > 0 .

$$
\mathrm{VPL}=-\frac{\mathrm{CFj}}{(1+\mathrm{TMA})^{\mathrm{j}}}>0
$$

onde:

Cfo $=$ Investimento Inicial

$\mathrm{CFj}=$ Fluxo Esperado de Benefícios Futuros

A análise do VPL, para efeito de se aceitar ou rejeitar um projeto de investimento é:

- $\quad$ se VPL > $0---\rightarrow$ aceitar o projeto

- $\quad$ se VPL $<0---\rightarrow$ rejeitar o projeto

O VPLa é uma variação do método do VPL. Enquanto o VPL concentra todos os valores do fluxo de caixa na data zero, no VPLa o fluxo de caixa representativo do projeto de investimento é transformado em uma série uniforme.

$$
\mathrm{VPLa}=V P L \times\left(\frac{i(1+i)^{n}}{(1+i)^{n}-1}\right)
$$

A análise do VPLa, para efeito de se aceitar ou rejeitar um projeto de investimento:

- $\quad$ se VPLa $>0---\rightarrow$ aceitar o projeto

- $\quad$ se VPLa $<0---\rightarrow$ rejeitar o projeto

O Índice Benefício/Custo (IBC) é uma medida de quanto se espera ganhar por unidade de capital investido.É uma razão entre o Fluxo Esperado de Benefícios de um projeto e o Fluxo Esperado de Investimentos necessários para realizá-lo.

Valor presente do fluxo de benefícios

$\mathrm{IBC}=$

Valor presente do fluxo de investimentos

A análise do IBC, para efeito de se aceitar ou rejeitar um projeto de investimento é: 


$$
\begin{aligned}
& \text { se IBC }>1---\rightarrow \text { aceitar o projeto } \\
& \text { se IBC }<1---\rightarrow \text { rejeitar o projeto }
\end{aligned}
$$

Outro indicador de risco de projetos de investimentos é o Pay-back, esse é importante dentro do processo de decisões de investimentos. É o número de períodos necessários para que o fluxo de benefícios supere o capital investido.

\section{A PRODUÇÃO DO CAFÉ NO PARANÁ: ANÁLISE DE RESULTADOS}

A região Norte do Paraná, terra roxa e muito fértil, era até poucas décadas atrás uma extensa floresta inexplorada. Por volta dos anos 40, esta região passa por uma grande transformação com o surgimento do café. O impacto econômico e social provocado pela cultura cafeeira pode ser comparado, sem exageros, aos impactos da cana-de-açúcar no Nordeste brasileiro no período colonial, ao do ouro na região das Minas Gerais no século XVIII.

Nesta região, o café transformou vazios geográficos em regiões prósperas e urbanizadas. Através dele, surgiram vários municípios, atraindo várias ondas migratórias, tanto de mineiros e paulistas, como de imigrantes europeus e asiáticos que juntamente com os brasileiros de diversas regiões, proporcionaram uma especificidade cultural singular.

Até a década de 70 o café gerou centenas de milhares de empregos, colocou alimento nas mesas de milhares de famílias e gerou muita riqueza, a ponto de ser o maior produtor nacional. A cultura cafeeira proporcionou oportunidades nas diversas etapas de sua produção: no plantio e capina das roças; na colheita, na comercialização e transporte até as máquinas de beneficiamento. Sem dúvida, o ciclo do café contribuiu de forma significativa e única para a formação deste Norte e Noroeste do Paraná forte, independente e diferente. A pesquisa realizada $(C O N A B, 2011)$ nas regiões produtoras de café no estado resultou na apuração dos dados referentes à estimativa final da área. No ano base da pesquisa o Paraná conta com 16.658 hectares (ha) em formação e 74.752 (ha) em produção. A safra paranaense de 2011 (CONAB, 2011) foi de 1.842 (mil sacas) beneficiadas, uma produtividade 19,4\% menor do que em 2011, queda essa na produção justificada pela bienalidade da cultura. O sistema de plantios adensados responde por $61,8 \%$ da área total e $59,7 \%$ da área colhida em 2011, o restante sendo o plantio tradicional. 


\subsection{A produção de café}

As informações básicas utilizadas neste trabalho foram obtidas através dos dados da SEAB/DERAL (2012), cuja as propriedades rurais representam os plantios de café tradicional do sistema de produção predominante no Paraná. Os dados refletem padrões médios das regiões paranaenses e podem diferir individualmente de um local para outro.

Foram obtidos os coeficientes técnicos SEAB/DERAL (2012), preparo de área, plantio, o uso de máquinas, insumos (mudas, herbicidas, fertilizantes, mão de obra) e preços pagos (insumos, máquinas e equipamentos, serviços e mão de obra).

As operações de cultivo do café são apresentadas a seguir:

Preparo da área - considerou-se que os produtores preparam o solo através das operações contratadas de aração, gradagens e subsolagem mecanizadas;

Plantio - realizado após o preparo do solo, marcação das linhas, abertura das covas e combate das formigas. O espaçamento utilizado foi o de $3 \mathrm{~m}$ x $2 \mathrm{~m}$, resultando em 1.667 plantas por hectare, mais o replantio estimado em resultando em 1.667 plantas por hectare, mais o replantio estimado em 10\%, totalizando 1.834 mudas/ha (Tabelas 2);

Controle das plantas daninhas - nos dois primeiros anos é feito, principalmente, através de herbicidas além de coroamento e roçadas manuais;

Custos - no cultivo do café, como na maioria das atividades, o maior custo ocorre no primeiro ano e refere-se à implantação e manutenção, em que as mudas constituem o principal componente na formação do custo no "Ano 1". Independentemente do desembolso do produtor, a mão de obra constitui-se em um item importante do custo no "Ano 1" e o principal item nos anos seguintes.

Nesse caso, considerou-se apenas o valor médio da diária paga na região, em torno de $\mathrm{R} \$ 20,00 \mathrm{dia} / \mathrm{homem}$.

Vale ressaltar que, neste trabalho, considerou-se apenas os custos operacionais de cultivo. Para maiores informações sobre custos florestais de produção, ver Graça et al., 2000 .

Produtividade - A produtividade média por hectare de café foi considerada de 18 sacas/ha.ano. Cumpre ressaltar que os plantios bem manejados podem atingir produtividades mais elevadas.

Preço - A comercialização de café (recebidos) teve com base a cotação do dia obtida através do site: http://g1.globo.com/economia/agronegocios/noticia/globo-ruralcotacoes.html, um dos principais indicadores econômicos dos produtores de café brasileiro. 


\subsection{Análise dos resultados}

A Tabela 2 apresenta a estimativa do custo de produção do café tradicional, sendo possível verificar a importância da mão de obra e dos insumos químicos.

Tabela 2 - Estimativa do Custo de Produção do Café Tradicional

\begin{tabular}{|c|c|c|c|c|}
\hline & & Produtividade: & 18 & SC 60kg/ha \\
\hline \multicolumn{2}{|r|}{ Especificação } & $\mathbf{R} \$ / \mathbf{h a}$ & $\mathrm{R} \$ / 60 \mathrm{~kg}$ & Participação (\%) \\
\hline 1 & - Operação de máquinas e implementos & 508.59 & 28.26 & 6.57 \\
\hline 2 & - Despesas de manutenção de benfeitorias & 45.37 & 2.52 & 0.59 \\
\hline 3 & - Mão de obra temporária & $3,694.89$ & 205.27 & 47.72 \\
\hline 4 & - Sementes/Mativas & - & - & - \\
\hline 5 & - Fertilizantes & 748.07 & 41.56 & 9.66 \\
\hline 6 & - Agrotóxicos & 122.35 & 6.80 & 1.58 \\
\hline 7 & - Despesas gerais & 105.95 & 5.89 & 1.37 \\
\hline 8 & - Transporte externo & 50.40 & 2.80 & 0.65 \\
\hline 9 & - Assistência técnica & 108.07 & 6.00 & 1.40 \\
\hline 10 & - PROAGRO/SEGURO & 99.34 & 5.52 & 1.28 \\
\hline & - Juros & 270.24 & 15.01 & 3.49 \\
\hline & TOTAL DOS CUSTOS VARIÁVEIS (A) & $\mathbf{5 . 7 5 3 , 2 7}$ & 319.63 & 74.30 \\
\hline 1 & - Depreciação de máquinas e implementos & 178.38 & 9.91 & 2.30 \\
\hline 2 & - Depreciação de benfeitorias e instalações & 62.90 & 3.49 & 0.81 \\
\hline 3 & - Sistematização e correção do solo & 243.90 & 13.55 & 3.15 \\
\hline 4 & - Cultura & 518.18 & 28.79 & 6.69 \\
\hline 5 & - Seguro do capital & 25.37 & 1.41 & 0.33 \\
\hline & - Mão-de-obra permanente & 523.60 & 29.09 & 6.76 \\
\hline & SUB-TOTAL (B) & $1,552.33$ & 86.24 & 20.05 \\
\hline 7 & - Remuneração do Capital próprio & 194.84 & 10.82 & 2.52 \\
\hline & - Remuneração da terra & 243.09 & 13.51 & 3.14 \\
\hline & SUB-TOTAL ( C ) & 437.93 & 24.33 & 5.66 \\
\hline & TOTAL DOS CUSTOS FIXOS (B+C) & $1,990.26$ & 110.57 & 25.70 \\
\hline & CUSTO OPERACIONAL $(\mathrm{A}+\mathrm{B})$ & $7,305.60$ & 405.87 & 94.34 \\
\hline & CUSTO TOTAL $(\mathrm{A}+\mathrm{B}+\mathrm{C})$ & $7,743.53$ & 430.20 & 100.00 \\
\hline
\end{tabular}

Fonte: SEAB/DERAL (2012)

O Quadro 1 apresenta a rentabilidade econômica do café e sua evolução no tempo.

Quadro 1 - Indicadores Econômicos de Plantios de Café Tradicional

\begin{tabular}{|l|c|c|c|c|}
\hline \multicolumn{3}{|c|}{ Investimentos } & Retorno Bruto & Retorno líquido \\
\hline TOTAL C.Var.(A) & 2011 & -5753.27 & & \\
\hline SUB-TOTAL (B) & 2011 & -1552.33 & & \\
\hline SUB-TOTAL ( C) & 2011 & -437.93 & & \\
\hline Investimento Inicial Total & 2011 & -7743.53 & 0 & 0 \\
\hline Investimento em & 2012 & -1990.26 & 0 & 0 \\
\hline Investimento em & 2013 & -1990.26 & 0 & 0 \\
\hline Investimento em & 2014 & -1990.26 & 7056.00 & 5065.74 \\
\hline Investimento em & 2015 & -1990.26 & 7056.00 & 5065.74 \\
\hline Investimento em & 2016 & -1990.26 & 7056.00 & 5065.74 \\
\hline Investimento em & 2017 & -1990.26 & 7056.00 & 5065.74 \\
\hline Investimento em & 2018 & -1990.26 & 7056.00 & 5065.74 \\
\hline Investimento em & 2019 & -1990.26 & 7056.00 & 5065.74 \\
\hline Investimento em & 2020 & -1990.26 & 7056.00 & 5065.74 \\
\hline Investimento em & 2021 & -1990.26 & 7056.00 & \\
\hline
\end{tabular}


Investimento Total

$-27646.13$

56448.00

35460.18

\begin{tabular}{|l|c|c|c|}
\hline Fluxo de caixa & Ano & Valor Anual & Fluxo Caixa \\
\hline Valor Líquido do Ano 2011 & 0 & -7743.53 & -7743.53 \\
\hline Valor Líquido do Ano 2012 & 1 & -1990.26 & -9733.79 \\
\hline Valor Líquido do Ano 2013 & 2 & -1990.26 & -11724.05 \\
\hline Valor Líquido do Ano 2014 & 3 & 5065.74 & -6658.31 \\
\hline Valor Líquido do Ano 2015 & 4 & 5065.74 & -1592.57 \\
\hline Valor Líquido do Ano 2016 & 5 & 5065.74 & 3473.17 \\
\hline Valor Líquido do Ano 2017 & 6 & 5065.74 & 8538.91 \\
\hline Valor Líquido do Ano 2018 & 7 & 5065.74 & 13604.65 \\
\hline Valor Líquido do Ano 2019 & 8 & 5065.74 & 18670.39 \\
\hline Valor Líquido do Ano 2020 & 9 & 5065.74 & 23736.13 \\
\hline Valor Líquido do Ano 2021 & 10 & 5065.74 & 28801.87 \\
\hline
\end{tabular}

\begin{tabular}{|c|c|c|c|c|}
\hline \multicolumn{3}{|c|}{ Para Cálculo Payback } & & \\
\hline Valor Anual VP & Fluxo Caixa VP & Ano & \multicolumn{2}{|c|}{ RESUMO } \\
\hline-7743.53 & -7743.53 & 2011 & TMA (a.a) & $9.75 \%$ \\
\hline-1990.26 & -9733.79 & 2012 & VPL & $\mathrm{R} \$ 11.433 .21$ \\
\hline-1990.26 & -11724.05 & 2013 & TIR & $25.43 \%$ \\
\hline 5065.74 & -6658.31 & 2014 & & \\
\hline 5065.74 & -1592.57 & 2015 & \multicolumn{2}{|c|}{ PAYBACK } \\
\hline 5065.74 & 3473.17 & 2016 & ANOS & 4 \\
\hline 5065.74 & 8538.91 & 2017 & MESES & 4 \\
\hline 5065.74 & 13604.65 & 2018 & & \\
\hline 5065.74 & 18670.39 & 2019 & & \\
\hline 5065.74 & 23736.13 & 2020 & & \\
\hline 5065.74 & 28801.87 & 2021 & & \\
\hline
\end{tabular}

Fonte: estimativa dos autores

TIR = Taxa Interna de Retorno; VPL = Valor Presente Líquido; VPLA = Valor Presente Líquido Anual. TMA = Taxa Mínima de Atratividade

Verifica-se que a partir do quarto ano há retorno bruto e somente no quinto ano há retorno líquido positivo. No período de onze anos verifica-se lucro positivo de aproximadamente $\mathrm{R} \$ 35.460,18$. A TIR encontrada foi de $25,43 \%$ maior que a TMA de 9,75\% (Taxa SELIC de março de 2012). O VPL foi de R\$11.433,21. O VPLa atingiu R\$ 1.501,79. O IBC alcançou 1,2826. Com base nestes indicadores, conclui-se que o projeto é viável financeira e economicamente.

O Quadro 2 apresenta o cálculo estimado do sequestro de carbono ${ }^{6}$ da biomassa vegetal total do café no Paraná.

Quadro 2 - Cálculo da biomassa vegetal total (t/ha) do Café no Paraná, 2012

\begin{tabular}{|c|c|c|c|c|c|}
\hline \multicolumn{6}{|c|}{ BVT $(\mathbf{t} / \mathbf{h a})=($ BAVT + BTAMP + BTACM + BAH + BH $)$} \\
\hline BVAT & BTAMP & BTACM & BAH & BH & BVT \\
\hline
\end{tabular}

\footnotetext{
6 Metodologia para estimar o estoque de carbono em diferentes sistemas de uso da terra / Luis Alberto Arevalo, Julio César Alegre e Luciano Javier Montoya Vilcahuaman. - Colombo: Embrapa Florestas, 2002. 41 p.: il. (Embrapa Florestas. Documentos, 73). ISSN 1517-536X.
} 


\begin{tabular}{|c|c|c|c|c|c|}
\hline 174.02586 & 11.142868 & 13.69738 & 0.45833 & 0.30017 & 199.62460 \\
\hline \multicolumn{6}{|l|}{ Onde: } \\
\hline \multicolumn{6}{|c|}{$\mathrm{BVT}=$ biomassa vegetal total } \\
\hline \multicolumn{6}{|c|}{$\mathrm{BAVT}=$ biomassa total de árvores vivas } \\
\hline \multicolumn{6}{|c|}{ BTAMP = biomassa total das árvores mortas em pé } \\
\hline \multicolumn{6}{|c|}{ BTACM = biomassa total das árvores caídas mortas } \\
\hline \multicolumn{6}{|c|}{ BAH = biomassa arbustiva e herbácea } \\
\hline \multicolumn{6}{|c|}{$\mathrm{BH}=$ biomassa da serrapilheira } \\
\hline
\end{tabular}

Fonte: coleta de dados e estimativa dos autores (Fev. 2012).

Para coleta de dados, os autores foram a campo. Em uma área de 100,00 m² (4,00 m x 25,00 m), com espaçamento de plantio de $0,50 \mathrm{~m}$ x 2,80m, foram encontrados 60 pés de café com a média de $8,67 \mathrm{~cm}$ DAP. Para o cálculo da biomassa de árvores mortas em pé (kg/árvore), considerou-se em média 4 pés por $\mathrm{m}^{2}$. Admitiu-se uma média de 2 árvores caídas mortas na área. O Quadro 3 apresenta a estimativa de preço e renda de créditos de carbono ${ }^{7}$.

Quadro 3 - Probabilidade de rendimento dos créditos de carbono

Total de hectares Paraná com base na fonte de dados da CONAB *

$74,752.00$ há

Sequestro de Carbono do Paraná em toda área**

14,922,338.27 t/há

Total de Sequestro de Carbono do Paraná considerando (1/3) da área, conforme legislação** 4,974,112.76 t/há

Estimativa de US $\$ 8,17$ por tonelada de carbono sequestrado, considerando $(1 / 3)$ da área** $\$ 40,638,501.25$

Fonte*: CONAB (2011)

Fonte**: estimativa dos autores a partir de Alegre, Arevalo, Montoya (2002)

Para o cálculo da estimativa de renda dos créditos de carbono foi utilizado a área total de produção do Paraná em (ha) com base nos dados da Companhia Nacional de Abastecimento (CONAB, 2011). Utilizou-se um terço da área total para calcular os valores dos créditos. Segundo ÁVILA (2012), as permissões para dezembro de 2012 do EU ETS (segurança para o esquema europeu de comércio de emissões) estão sendo negociadas em apenas $€ 6.14$ (\$ 8.17) por tonelada, cotações do dia 02 de abril de 2012.

\section{CONCLUSÃO}

A análise dos resultados permite concluir que a produção de café no Paraná é importante para a economia local e regional no que tange à geração de empregos,

\footnotetext{
${ }^{7}$ CONAB, Companhia Nacional de Abastecimento Acompanhamento da Safra Brasileira Café Safra 2011 quarta estimativa, dezembro/2011. Brasília: 2011.
} 
estabilidade do homem no campo, investimentos tecnológicos e científicos, políticas agrárias e distribuição de renda. Também é um dos mais importantes componentes da pauta de exportação. A análise financeira da viabilidade econômica e rentabilidade do plantio tradicional foi positiva - análise da TIR revela um retorno superior a 25\%; o VPL foi de R\$11.433,21; o VPLa atingiu R \$ 1.501,79 e o IBC alcançou 1,2826 - e também foi possível verificar a sua sustentabilidade e viabilidade social. Logo, as políticas públicas de incentivo ao plantio de café no Paraná e em outras regiões do Brasil devem ser estimuladas, pois o cultivo do café contribui para reduzir o êxodo rural e o aumento das grandes concentrações urbanas. Investimentos em qualidade diferentemente do passado (onde se propagava a quantidade), elevarão o valor agregado e contribuirão para retornos positivos na balança comercial paranaense e brasileira, gerando riqueza e sustentabilidade produtiva, em um quadro onde é possível incrementar as exportações futuras de café de qualidade internacional reconhecida.

\section{REFERÊNCIAS}

ALEGRE, J. C.; AREVAlO, L. A.; MONTOYA, L. J. V. Metodologia para estimar o estoque de carbono em diferentes sistemas de uso da terra. Colombo: Embrapa Florestas, 2002. 41 p.

ÁVILA, F. Queda nas emissões da União Europeia derruba preço do carbono. Disponível em: Instituto CarbonoBrasil/Thomson Reuters Point Carbon. Disponível em: http://www. institutocarbonobrasil. org.br/noticias/noticia=730112. Acesso em: 03 de abr. 2012.

BNDES. Programa Nacional de Fortalecimento da Agricultura Familiar - PRONAF. 2010. Disponível em:<http://www.bndes.gov.br/programas/agropecuarios/pronaf.asp $>$. Acesso em: 02 out. 2011.

BRASIL. MCT, Ministério da Ciência e Tecnologia. O que é o efeito estufa? Disponível em: <http://www.mct.gov.br/index.php/content/view/49252.html> Acesso em: 01 out. 2011.

BRASIL. MCT, Ministério da Ciência e Tecnologia. Protocolo de Quioto. Disponível em: <http://www.mct.gov.br/index.php/content/view/17329.html> Acesso em: 01 out. 2011.

BRASIL. MCT, Ministério da Ciência e Tecnologia. Status atual das atividades de projeto no âmbito do Mecanismo de Desenvolvimento Limpo (MDL) no Brasil e no mundo. Disponível em: <http://www.mct.gov.br/upd_blob/0217/217019.pdf> Acesso em: 17 dez. 2011.

BRASIL. MCT, Ministério da Ciência e Tecnologia. Texto da convenção: Artigo 2 - Objetivos. Disponível em: <http://www.mct.gov.br/index.php/content/view/4089. html> Acesso em: 17 dez. 2011.

BRASIL. MMA, Ministério do Meio Ambiente. Secretaria de Articulação Institucional e Cidadania Ambiental. Agenda 21. Disponível em: <http://www.mma.gov.br/sitio/index.php?ido= conteudo.monta\&idEstrutura=18>. Acesso em: 05 nov. 2011. 
ClARO, P. B. de O; ClARO, D. P.; AMÂNCIO, R. Entendendo o conceito de sustentabilidade nas organizações. Revista de Administração. RAUSP v.43 n.4 São Paulo out./dez. 2008. Disponível em: <http://www.revistasusp.sibi.usp.br /scielo.php?pid=S008021072008000400001 \&script=sci_arttext $>$. Acesso em: 08 out. 2011.

CLEMENTE, Ademir, HIGACHI, Hermes Y. Economia e desenvolvimento regional. São Paulo: Atlas, 2000.

CONAB, Companhia Nacional de Abastecimento Acompanhamento da Safra Brasileira Café Safra 2011 quarta estimativa, dezembro/2011. Brasília: 2011.

CONEJERO, Marco Antonio. Marketing de créditos de carbono: Um estudo exploratório. 2006. 206 folhas. Dissertação de Mestrado, USP, Ribeirão Preto. Disponível em: <http://www. fundacaofia.com.br/pensa/anexos/biblioteca/572007152424_Carbon_Dissertation_Conejero.pdf> Acesso em: 26 nov. 2011.

COSTA, S. S. T. Introdução á Economia do meio Ambiente. Análise. Porto Alegre. v. 16, n. 2, p. 301-323 ago./dez. 2005. Disponível em: <http://revistaseletronicas.pucrs.br/ojs/index.php/ face/article/view/276>. Acesso em: 2 out. 2008.

DAMASCENO, J.J; MATA, H.T.C. Economia e Meio Ambiente: Uma abordagem na perspectiva das Teorias do Valor - Terabalho e Valor - Utilidade. Anais do XII Seminário de Iniciação Científica da UFSC, Florianópolis, 2002, p. 418-419.

DICUM, G.; LUTTINGER, N. The Coffee Book: anatomy of industry from crop to the last drop. New York: The New York Press, 1999, 196p.

DONAIRE, D. Gestão ambiental na empresa. 2.ed. São Paulo: Atlas, 1999.

EMBRAPA. Economia Cafeeira. Consórcio Brasileiro de Pesquisa e Desenvolvimento do Café. 1997. Disponível em: <http://www22.sede.embrapa.br/cafe/consorcio/home_4.htm>. Acesso em: Out. 2008.

FORATO, C. Auditoria de certificação ambiental. São Paulo: Pearson Prentice Hall, 2010. 182 p.

GEORGESCU-ROEGEN, Nicolas. Energy and Economy Myths. New York: Pergamon Press, 1976.

LOPES, I. V. O mecanismo de desenvolvimento limpo: guia de orientação. Rio de Janeiro: Fundação Getulio Vargas, 2002.

BRASIL. MAPA, Ministério da Agricultura, Pecuária e Abastecimento - Secretaria de Produção e Agroenergia. Plano Nacional de Agroenergia 2006-2011. Brasília, DF. Embrapa Informação Tecnológica, 2006. 110 p. Disponível em: <http://www.agricultura.gov.br/arq_ editor/file/ Ministerio/planos\%20e\%20pro gramas/PLANO\%20NACIONAL\%20DE\% 20AGROENERGIA. pdf> Acesso em: 01 out. 2011.

PORTAL São Francisco. Aquecimento global. 2012. Disponível em: http://www.portalsao francisco.com.br/alfa/meio-ambiente-efeito-estufa/aquecimento-global-11.php. Acesso em: 09 abr. 2012.

PORTUGAL, A. D. O Desafio da Agricultura Familiar. 2004. Disponível em <http://www.embrapa. br/imprensa/artigos/2002/artigo.2004-12-07.2590963189/>. Acesso em: 2 set. 2011. 
ROMEIRO, A. R. Economia ou economia política da sustentabilidade. In: MAY, P. H.; LUSTOSA, M. C.; VINHA, V. (Org.) Economia do meio ambiente: teoria e prática. Rio de Janeiro: Elsevier, 2010.

SISTER, G. Mercado de carbono e Protocolo de Kyoto. 2. ed. Rio de Janeiro: Elsevier, 2008.

TOLEDO, P. C.i; BALLALAIA, A. L.; FEIJÓ, C. C. C. O aquecimento global e os projetos de mecanismo de desenvolvimeno limpo. In: PIRES, E. O.; TOZATO, H. C. Elaboração e análise de projetos de conservação e proteção ambiental. São Paulo: Pearson Education do Brasil, 2009. Uni. 5, p. 76-125.

VEIGA FILHO, A. A.; ASSE, L. C.; SOUZA, M. C. M. A produção da pesquisa para a agricultura: o caso do café no estado de São Paulo. Agricultura em São Paulo, Ano XXXII, tomos I e II, 1985, 83-106.

VIEIRA, R.; ROCHA, R. Economia e Meio Ambiente. Bionotícias. Conselho Regional de Biologia 2. Regional Rio de janeiro e Espírito Santo. Nov./dez. 2005. Disponível em: http://www.crbio2.org.br/bionoticias/Dez05.pdf >. Acesso em: 12 out. 2008.

WWF, Brasil. Pegada Ecológica? O que é isso? Disponível em: <http://www. wwf.org.br/index.cfm> Acesso em: 29 out. 2011.

WWF, Brasil. Planeta vivo relatório 2010: Biodiversidade biocapacidade e desenvolvimento. Disponível em: <http://assets.wwf.org.br/downloads/08out10_ planetavivo_relatorio2010_ completo_n9.pdf> Acesso em: 03 dez. 2011.

SEAB/DERAL. Secretaria de Estado da agricultura e do abastecimento do Paraná, SEAB, Departamento de Economia Rural, DERAL. 2012. Disponível em: < www.agricultura.pr.gov.br>. Acesso em: 21 mar. 2012.

WWW.GLOBO.COM. Globo Rural - Agronegócio - Cotações do dia. Disponível em: http://g1.globo. com/economia/agronegocios/noticia/globo-rural-cotacoes.html. Acesso em: 21 de março de 2012.

WWW.RECEITA.FAZENDA.GOV.BR - Taxa de juros Selic. Disponível em: http://www.receita.fazenda.gov.br/pagamentos/jrselic.htm\#Taxa_de_Juros_Selic - Acesso em: 07 de março de 2012.

WWW.UOL.COM.BR - Uol - Noticias e Economia - Câmbio. Disponível em http://economia.uol.com.br/cotacoes/cambio.jhtm - Acesso em: 18 de maio de 2012.

ZÔMPERO, A. F. et al. Gestão ambiental: Fundamentos lógicos, críticos e analíticos. Londrina: Unopar, 2008. 210 p.: il. 